\title{
Kentiçi Kavşakların Mikrosimülasyon Yöntemiyle Modellenmesi: Erzurum İli Örneği*
}

\author{
Fatih İrfan Baş ${ }^{1 *}$, Muhammed Ali Çolak ${ }^{2}$, Ahmet Oğuz Demiriz ${ }^{3}$, Halim Ferit Bayata ${ }^{4}$, Osman Ünsal Bayrak ${ }^{5}$ Ömer \\ Faruk Keleş ${ }^{6}$, Yusuf Mazlum 7 , Mehmet Oğuzhan Gürel ${ }^{8}$, Muhammed Sami Demircioğlu ${ }^{9}$

\begin{abstract}
${ }^{1}$ Erzincan Binali Yıldırım Üniversitesi, Mühendislik Fakültesi, İnşaat Mühendisliği Bölümü, Erzincan, Türkiye (ORCID: 0000-0002-0845-060X) ${ }^{2}$ Erzincan Binali Yıldırım Üniversitesi, Mühendislik Fakültesi, İnșaat Mühendisliği Bölümü, Erzincan, Türkiye (ORCID: 0000-0003-4990-6674)

${ }^{3}$ Erzincan Binali Yıldırım Üniversitesi, Mühendislik Fakültesi, İnşaat Mühendisliği Bölümü, Erzincan, Türkiye (ORCID: 0000-0002-6680-8569)

${ }^{4}$ Erzincan Binali Yıldırım Üniversitesi, Mühendislik Fakültesi, İnşaat Mühendisliği Bölümü, Erzincan, Türkiye (ORCID: 0000-0001-8274-8888)

${ }^{5}$ Atatürk Üniversitesi, Mühendislik Fakültesi, İnşaat Mühendisliği Bölümü, Erzurum, Türkiye (ORCID: 0000-0003-4039-1248)

${ }^{6}$ Erzincan Binali Yıldırım Üniversitesi, Mühendislik Fakültesi, İnşaat Mühendisliği Bölümü, Erzincan, Türkiye (ORCID: 0000-0001-6149-572X)

${ }^{7}$ Erzincan Binali Yıldırım Üniversitesi, Mühendislik Fakültesi, Geoteknik Bölümü, Erzincan, Türkiye (ORCID: 0000-0003-2957-2822)

${ }^{8}$ Erzincan Binali Yıldırım Üniversitesi, Dursun Yıldırım MYO, Tapu Kadastro Bölümü, Erzincan, Türkiye (ORCID: 0000-0001-9988-9169)

${ }^{9}$ Erzincan Binali Yıldırım Üniversitesi, Mühendislik Fakültesi, İnșaat Mühendisliği Bölümü, Erzincan, Türkiye (ORCID: 0000-0002-0295-9309)
\end{abstract}

(Konferans Tarihi: 5-7 Mart 2020)

(DOI: 10.31590/ejosat.araconf58)

ATIF/REFERENCE: Baş, F. İ., Çolak, M. A., Demiriz, A. O., Bayata, H. F., Bayrak, O. Ü., Keleş, Ö. F., Mazlum, Y., Gürel, M. O. \& Demircioğlu, M. S. (2020). Kentiçi Kavşakların Mikrosimülasyon Yöntemiyle Modellenmesi: Erzurum İli Örneği. Avrupa Bilim ve Teknoloji Dergisi, (Özel Sayı), 444-451.

\section{$\ddot{\mathbf{O} z}$}

Gelişen teknolojiye bağlı olarak dünya genelinde olduğu gibi Erzurum il merkezinde de araç sayısında artış meydana gelmiş ve Erzurum kent içi ana arter ve ana arterleri üzerinde bulunan kavşaklarda trafik hacminin artmasına sebep olmuştur. Erzurum'da son beş yılda motorlu taşıt sayısı 16.762 artarak 119.108'e ulaşmıştır. Artan trafik hacmi özellikle şehrin en merkezi kavşağı konumunda olan Tebrizkapı Kavşağı'nı etkilemiştir. Tebrizkapı Kavşağı kentin en işlek merkezi olan Cumhuriyet Caddesi, Karskapı Caddesi ve en önemli alışveriş merkezlerinden biri olan Taş Mağazalar Caddesi arasında kaldığından özellikle sabah mesai başlangıç saatleri ve akşam mesai bitim saatlerinde ciddi trafik yoğunluklarına maruz kalmaktadır. Sayım sonuçları doğrultusunda Tebrizkapı Kavşağı'nda sabah zirve saati 07:45 ile 08:45 ve akşam zirve saati 16:45 ile 17:45 arasında olduğu belirlenmiş ve simülasyon yapılırken yoğunluk olan zirve saatlerin trafik hacimleri alınmıştır.

Bu çalışmada, AIMSUN yazılımı kullanılarak Tebrizkapı Kavşağı'nın mevcut durum ve farklı kavşak tipleri ile tasarımları Mikrosimülasyon ile simüle edilmiştir. Üretilen modellerin doğruluğunu ölçmek için trafik hacimleri üzerinde doğrulama testi olarak kullanılan GEH (Geoffrey E. Havers) formülünden faydalanılmıştır. Mevcut durumdaki gecikme süresi 41,10 saniye ve bekleme süresi 26,85 saniye olarak bulunmuştur. Mevcut durumdaki kavşak tipi değiştirilerek Modern Dönel Kavşak ve Farklı Düzey Kavşak tasarlanarak simülasyonları yapılmıştır. Yeni yapılan tasarımların gecikme süreleri Modern Dönel kavşak için 9,21 saniye, Farklı Düzey Kavşak için 5,03 saniye, bekleme süreleri ise Modern Dönel Kavşak için 1,66 saniye ve Farkl1 Düzey Kavşak için 1,20 saniye olarak bulunmuştur. Simülasyonlar sonucunda gecikme süresi ve bekleme süresi faktörleri dikkate alınarak en uygun kavşak tipi Farklı Düzey Kavşak olarak bulunmasına rağmen yapım maliyetinin çok yüksek olmasından dolayı Modern Dönel Kavşak yapılması en uygun seçim olarak belirlenmiştir.

Anahtar Kelimeler: AIMSUN, Mikrosimülasyon, Gecikme Süresi, Bekleme Süresi

\footnotetext{
* This paper was presented at the International Conference on Access to Recent Advances in Engineering and Digitalization (ARACONF 2020).
} 


\title{
Modeling urban intersections with micro-simulation method: Erzurum province sample
}

\begin{abstract}
Depending upon improving technology, increase at the number of vehicles has appeared in Erzurum province as in all around the world, and this has caused increase at traffic volume in main arteries and intersections on these inner-city main arteries. Because Tebrizkapı Junction is located between Cumhuriyet Street, Karskapı Street which is the busiest center of the city, and Taş Mağazalar Street, one of the most important shopping centers, it is exposed to serious traffic intensity especially in the morning working hours and evening working hours. In accordance with the numbers of countings, peak hour for the morning in Tebrizkap 1 intersection is between 7.45 and 8.45 a.m., and the peak hour for the evening is between 4.45 and 5.45 p.m. The traffic volumes of peak hours were used during the simulation.

In this study, using the AIMSUN software, the current state of the Tabrizkap1 Junction, and the different junction types and designs are simulated by Micro-simulation. The GEH (Geoffrey E. Havers) formula, which is used as a verification test on traffic volumes, was used to measure the accuracy of the models produced. The delay time and the stop time for the existing situation were 41.10 and 26.85 seconds, respectively. By changing the type of the existing intersection, the Roundabout and Grade Seperated Junctions were designed and simulated. The delay times for the new designs were found as 9.21 and 5.03 seconds for Roundabout and Grade Seperated Junction respectively. The stop times for the new designs were found 1.66 and 1.20 seconds for Roundabout and Grade Seperated Junctions respectively. As a result of the simulations, the most appropriate intersection type was found as Grade Seperated Junction considering the delay time and stop time factors. Due the high construction cost of the Grade Seperated Junction, the Roundabout junction has been found as the most appropriate choice
\end{abstract}

Keywords: AIMSUN, Microsimulation, Delay time, Stop time

\section{Giriş}

Ulaşım, insanların veya eşyaların yer değiştirmeleri olarak tanımlanmaktadır. Ulaşımdan dolayı meydana gelen hareketler "trafik" deyimiyle adlandırılır. Ulaşım ve trafik bir bütün olarak düşünülmelidir. Ülkemizde artan nüfus, dünyada gelişen teknoloji ve buna bağlı olarak artan araç sahipliliği mevcut yolların yetersiz kalmasına neden olmaktadır. Daha konforlu ve hızlı bir ulaşım sağlayabilmek için ulaşım sistemlerinin, yol güzergahlarının, kavşak tiplerinin ve sinyalizasyon gibi parametrelerin geliştirilmesi gerekmektedir. Bu bağlamda mevcut trafik ve gelecekte oluşması beklenen trafik artışlarının tahmin edilerek ulaşım sistemi, yollar ve trafiğe etki eden bütün parametreler bu doğrultuda modellenmelidir. Modellemeler yapılırken trafik simülasyonları yaygın olarak kullanılmaktadır. Simülasyonlar sayesinde alternatif çözüm önerileri etkili bir şekilde analiz edilirek güvenli ve düşük maliyetli olarak değerlendirilebilirler (Park and Schneeberger, 2003; Siddharth and Ramadurai, 2013). Son yıllarda trafik ve trafik yönetimi için mikro-simülasyon uygulamaları üzerine birçok çalışma yapılmıştır (Gomes et al, 2004; Tianzi et al 2013; Alkheder, 2016; Bayata and Bayrak, 2018; Zlatkovic et al, 2019).

Bu çalışmada stratejik konumu, gelişmeye açık olan ve bölgenin lokomotifliğini üstlenen Erzurum ili Tebrizkapı Kavşağı çalışma alanı olarak belirlenmiştir. Öncelikle haftalık, günlük ve saatlik trafik sayımları yapılarak zirve saat trafiği bulunmuş ve mevcut durum AIMSUN programı ile modellenmiştir. Daha sonra kavşak tipi değiştirilerek AIMSUN programı ile tekrar modellenmiş ve birbirleriyle karşılaştırmaları yapılmıştır.

\section{Materyal ve Metot}

Verilerin sanal ortama aktarılma olayına simülasyon denilmektir. Çok çeşitli alanlarda kullanılmaktadır. Bunlardan birisi de trafik alanıdır. Trafik simülasyonu, simüle edilen bölgenin gerçek trafik hacminin elektronik ortamda oluşturulan bir benzetmesidir. Bu simülasyonlar sayesinde trafik gecikmeleri, yakıt tüketimleri, yoğunluk, emisyon ölçümleri, kuyruk uzunlukları ve seyahat süreleri gibi birçok parametre hesaplanabilmektedir. Trafik çözümlerinin maliyetli olmasından dolayı öncelikli olarak simüle edilmesi zaruri hale gelmiştir. Trafik simülasyonları 3 seviyede modellenebilmektedir. Bunlar; mikro simülasyon (tek kavşak), mezoskopik simülasyon (2-5 kavşak) ve makro simülasyondur (alanın tamamı). Günümüzde birçok trafik simülasyon programı kullanılmaktadır. Bunlardan bazıları; AIMSUN, VISSIM, AVENUE, SIDRA, SUMO vb.dir. Bu çalışmada AIMSUN programı kullanılmıştır.

AIMSUN (Advanced Interactive Microscopic Simulator for Urban and Non-Urban Networks) kentiçi veya kentdışı trafik ağları için geliştirilmiş mikroskobik simülatörün bir kısaltmasıdır. Bu program başlangıçta yalnızca mikroskobik simülasyonlar yapabilmekte iken günümüzde daha da geliştirilerek mezoskopik ve makroskopik seviyelerde simülasyon modelleri de yapabilir hale getirilmiştir.

\section{1. Çalışma Alanı}

Doğu Anadolu Bölgesinin gelişmiş şehirlerinden birisi olan Erzurum, $25066 \mathrm{~km} 2$ alana sahip ve şehir merkezi nüfusu 762062 olan bir ilimizdir (TÜİK, 2020). Tarihi İpek yolu üzerinde bulunmasından dolayı jeopolitik olarak önemli bir yere sahiptir. Şehre 
ulaşım, tren, karayolu ve havayolu ile sağlanmaktadır. Bu çalışmada, yaklaşık 4672 araçlık YOGT değerine sahip Erzurum ili Tebrizkapı Kavşağı çalışılmıştır (Şekil 1). Tebrizkapı Kavşağı, Erzurum ili genelindeki en yoğun kavşaklardan birisidir.

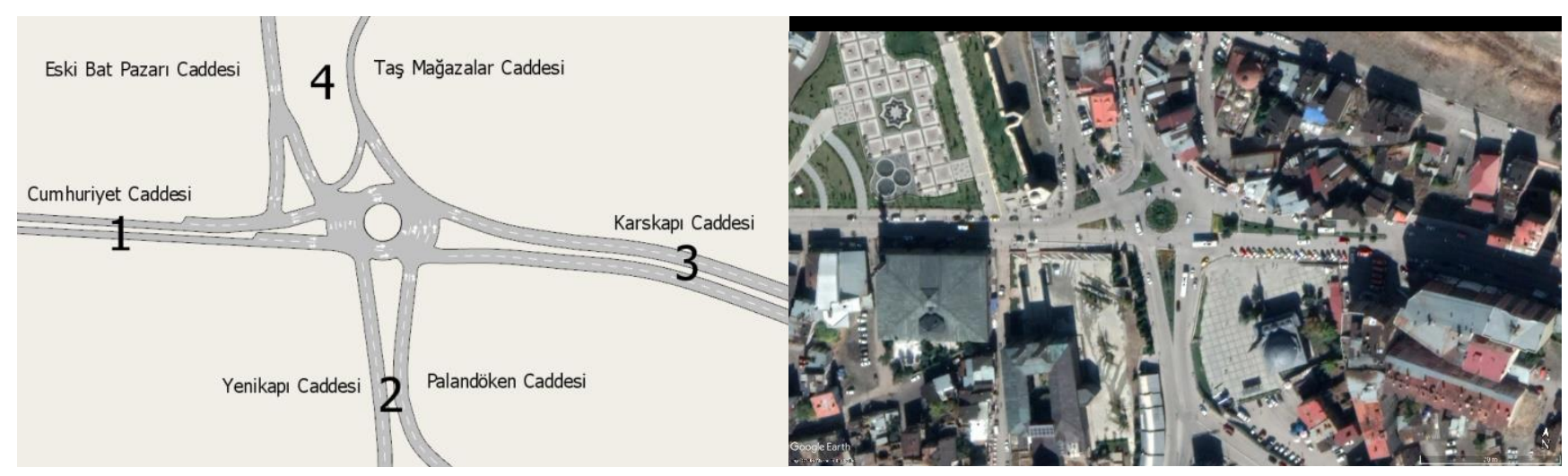

Şekil 1. Tebrizkapı Kavşă̆g (GoogleEarth, 2020)

\subsection{Mikrosimülasyon Model Oluşturulması}

Tebrizkapı Kavşağı'nın AIMSUN programı ile hazırlanan mevcut duruma ait model görünümleri Şekil 2'de verilmiştir.

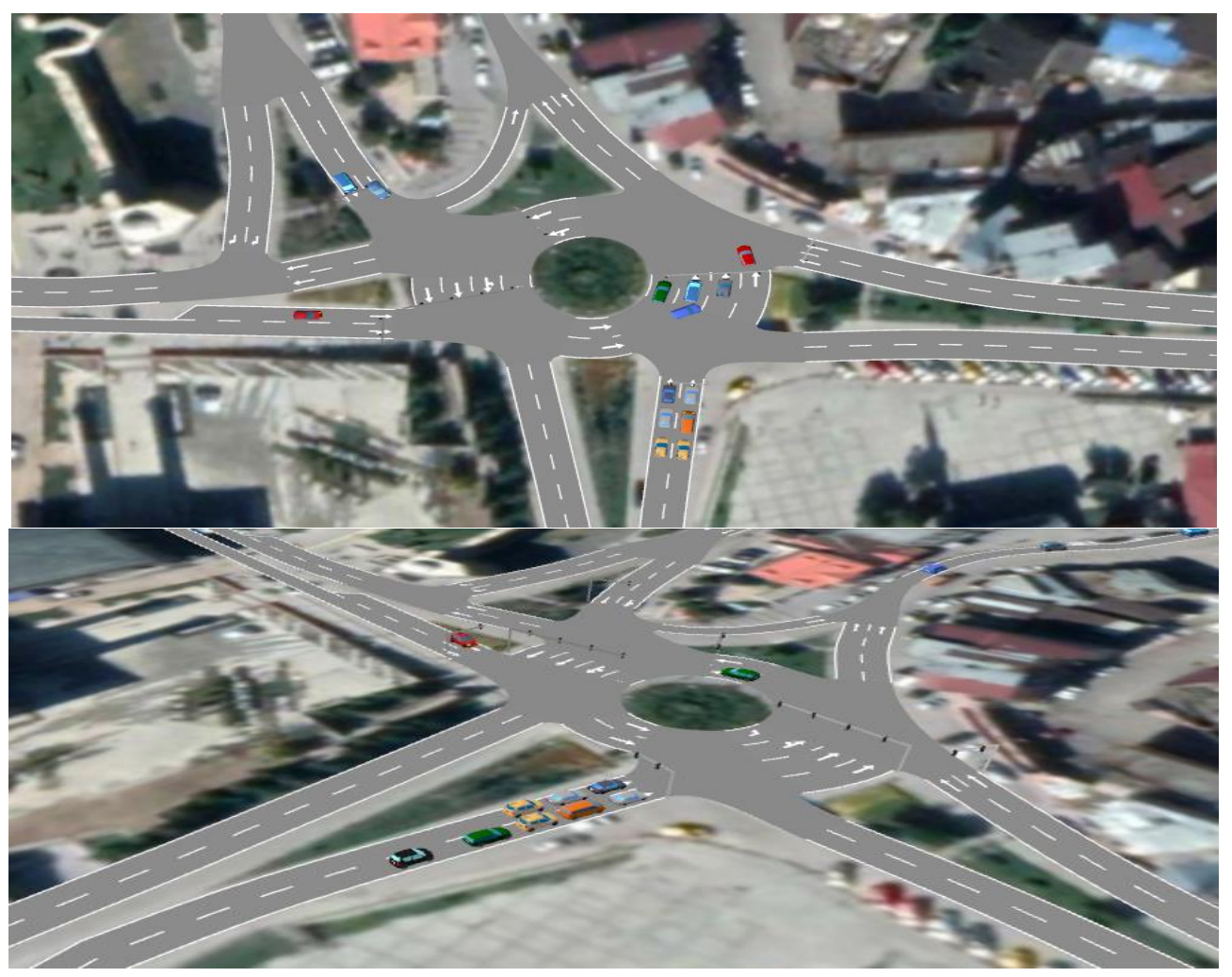

Sekil 2. Mevcut durum modeli

Ele alınan kavşak, Cumhuriyet Caddesi, Taşmağazalar, Eski Bat Pazarı, Palandöken, Karskapı ve Yenikapı Caddeleri arasında yer almaktadır. Kavşakta sinyalizasyon mevcuttur ve yedi ayrı noktaya trafik ışığı konumlandırılmış̧ır. Trafik sşıklarının konumları Şekil 3 'te verilmiştir. Erzurum ilinin en işlek caddesi olan Cumhuriyet Caddesi bitiminde olduğu için bu kavşağa gelen trafik yoğunluğu zirve saatlerde artmaktadır. Bu problemi çözebilmek amacıyla AIMSUN programı ile kavşak tipleri değiştirilerek modeller kurulmuş ve mevcut durum ile karşıllaştırılmıştır. 


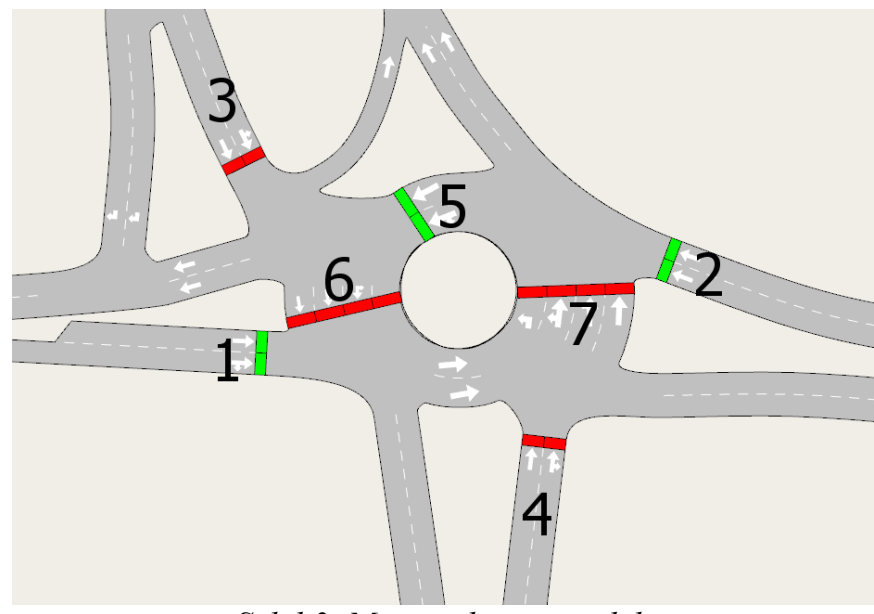

Şekil 3. Mevcut durum modeli

\subsection{Mikrosimülasyon Model Oluşturulması}

Trafik yoğunluğunun sabah 07:45-08:45 ve akşam 16:45-17:45 saatleri arasında olduğu yapılan çalışmalarda tespit edilerek trafik sayımları bu zirve saatlerde yapılmıştır. Tablo-1' de kavşak kollarında gerçekleşen trafik sayım sonuçları verilmiştir.

Tablo 1. Taşıt sayım sonuçları

\begin{tabular}{l|c}
\hline \multicolumn{1}{c|}{ Kesim Adı } & Toplam Taşıt (ta/sa) \\
\hline Cumhuriyet Caddesi (1-3 istikameti) & 325 \\
\hline Karskapı Caddesi (3-1 istikameti) & 233 \\
\hline Eski Bat Pazarl Caddesi (4-2 istikameti) & 202 \\
\hline Palandöken Caddesi (2-4 istikameti) & 540 \\
\hline
\end{tabular}

Tebrizkapı Kavşağı'na ait geometrik özellikler (şerit genişliği, şerit sayısı ve kavşak yarıçapı vb.) ve diğer detaylar yapılan çalışmalar ile elde edilerek simülasyon modelleri hazırlanmıştır. AIMSUN programı, mikro simülasyon modelin oluşturulmasında kullanılmıştır. Mevcut trafik kullanılarak AIMSUN programı ile model oluşturulmuş ve daha sonra kavşak tipi değiştirilerek oluşturulan yeni modeller ile karşılaştırılması yapılmıştır (Siddharth and Ramadurai, 2013). Mikro-simülasyon programları ile üretilen modellerin kalibre edilmesi gerekmektedir. Kalibrasyon için GEH formülü (Alomari et al, 2016; Karakikes et al, 2016), bağıl hata (Yu et al, 2006; Song et al 2012) gibi farklı yöntemler kullanılmaktadır. Bu çalışmada üretilen modellerin kalibrasyonunu ölçmek için araç hacimleri üzerinde doğrulama testi olarak kullanılan GEH (Geoffrey E. Havers) formülünden faydalanılmıştır (Jeihani et al, 2013; Oketch and Carrick, 2005). Kalibrasyonda kavşağa giren araç hacimleri kullanılmıştır. Modifiye edilmiş Ki-kare testi olarak da bilinen GEH formülünün kullanımına ilişkin detaylı bilgiler Russo (2008) ve Shanktar et al. (2013) çalışmasında verilmiştir. AIMSUN ile kurulan modelde veri toplama noktalarından alınan seyahat süresi ölçüm sonuçları Havers'in çalışmasına göre kalibre edilmiştir. Tablo 2' de verilen sonuçlara göre GEH kriterleri sağlanmaktadır ve kurulan AIMSUN modelinden elde edilen sonuçların kullanılabileceği görülmektedir.

Tablo 2. Kalibrasyon ve doğrulama dĕ̆erleri

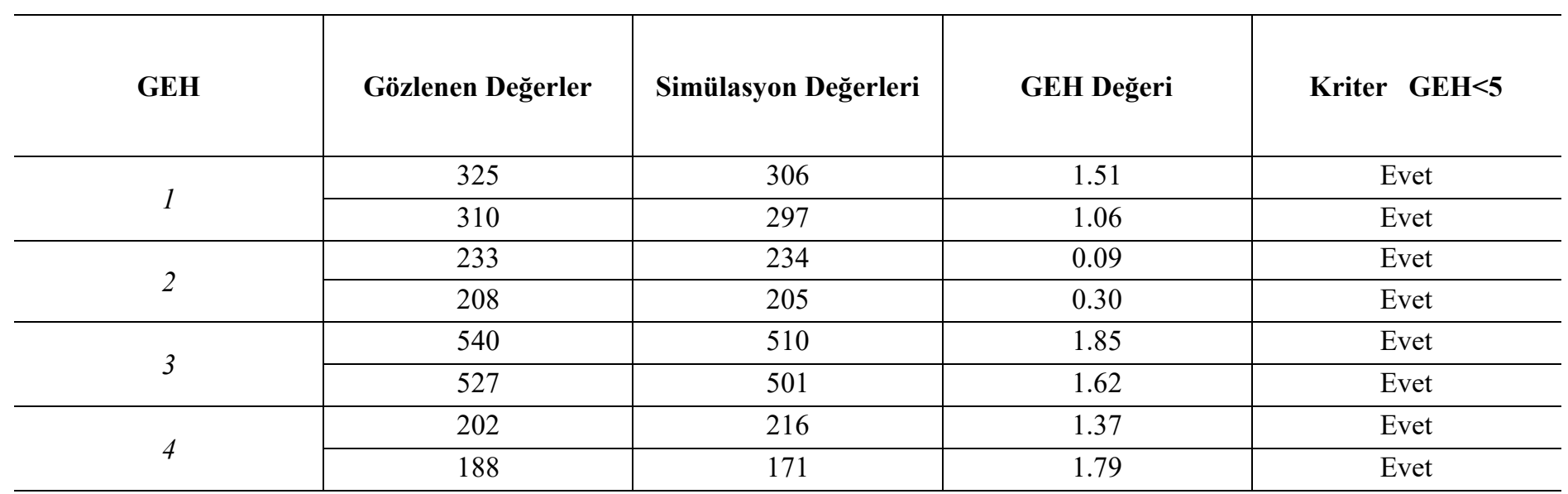




\subsection{Kavşakta Gözlenen Problemler}

Çalışma konusu olan kavşak, Erzurum ilinde en fazla yoğunluğun yaşandığı kavşaklardan birisidir. Sabah ve akşam zirve saatlerindeki trafik yoğunluğundan dolayı kuyruk uzunlukları görülmekte ve bağlı olduğu ana caddelerin trafik tıkanıklıklarına ve dolayısıyla da trafik kazalarına neden olduğu görülmektedir. Kavşak içerisinde ve bağlantı yollardaki sinyalizasyonlar nedeniyle sürücüler iki kere, yoğunluk olduğu zamanlarda ise 3 veya 4 kere trafik ışıklarında beklemek zorunda kaldıkları için sürücülerde dikkat dağılımı ve sürücülerin trafik kurallarına uymama eğiliminde oldukları gözlemlenmiştir. Ayrıca kavşaklardaki sinyalizasyon programında yaya fazının olmamasından dolayı yaya geçişlerinde yaşanan tereddütlerden dolayı kazaların meydana geldiği gözlemlenmiştir.

\section{Araştırma Sonuçları ve Tartışma}

Tebriz kapı kavşağı için altgeçit ve modern dönel kavşak uygulamalarının olduğu iki çözüm önerisi belirlenmiştir.

\subsection{Modern Dönel Kavşak (Roundabout) yapılması}

Modern dönel kavşaklar sinyalizasyonu ortadan kaldırdı̆̆ı için gecikme ve bekleme sürelerinde çok ciddi azalmalar oluşturmaktadır. Bu sayede daha yüksek kapasite/şerit imkânı verebilirler (KGM, 2005) Ayrıca kavşak yaklaşımlarında yatay kurba ile kavşağa giriş, sürücülerin hızlarını azaltmalarına neden olarak muhtemel kaza sayılarını azalmakta veyahut da kaza şiddetini azaltmaktadır (KGM, 2020; GDH, 2006). Bu çalışmada, Tebrizkapı kavşağında oluşan gecikmelerden dolayı alternatif olarak roundabout tarzı kavşak yapılması önerilmektedir. Daha önce yapılmış olan araştırmalarda modern dönel kavşakların kaza sayılarını azalttığı, gecikme sürelerini azalttığı ifade edilmektedir (Tanyel and Yayla, 2010). Önerilen alternatif mevcut geometrinin izin verdiği ölçüde modellenmiş olup ada yarı çap1 20 metre olarak oluşturulmuş ve mevcut giriş çıkış bağlantıları yeniden düzenlenmiştir. Oluşturulan model Şekil 4.'te verilmiştir. Gecikme süresi sonuçları, mevcut durumla karşılaştırılmalı olarak Şekil 5' te verilmiştir. Bekleme süreleri ise Şekil 6'da verilmiştir.

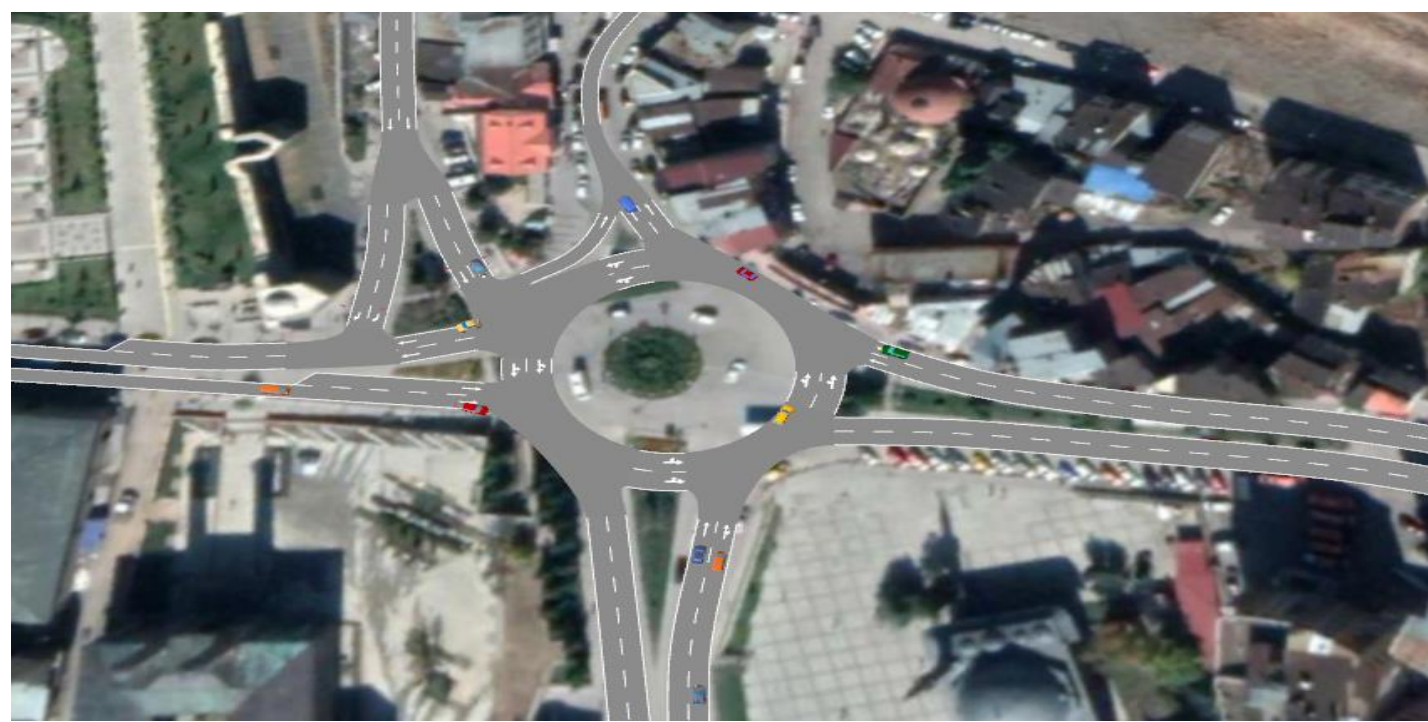

Şekil 4. Oluşturulan modern dönel kavşak

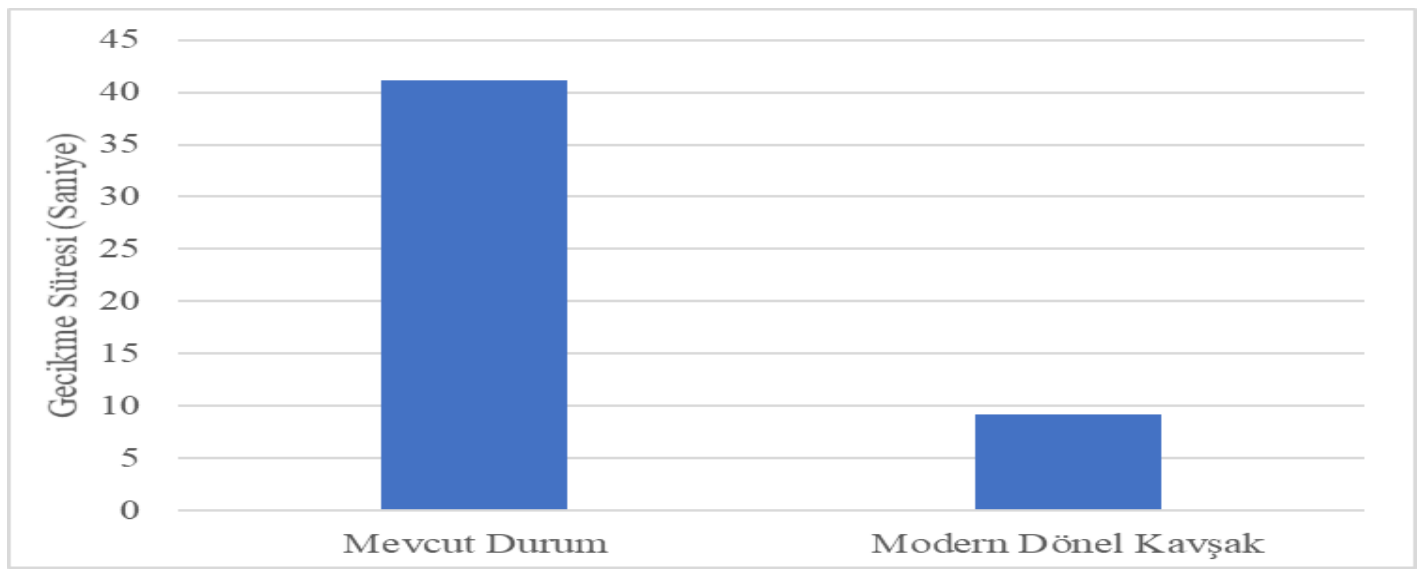

Şekil 5. Gecikme Süreleri 
European Journal of Science and Technology

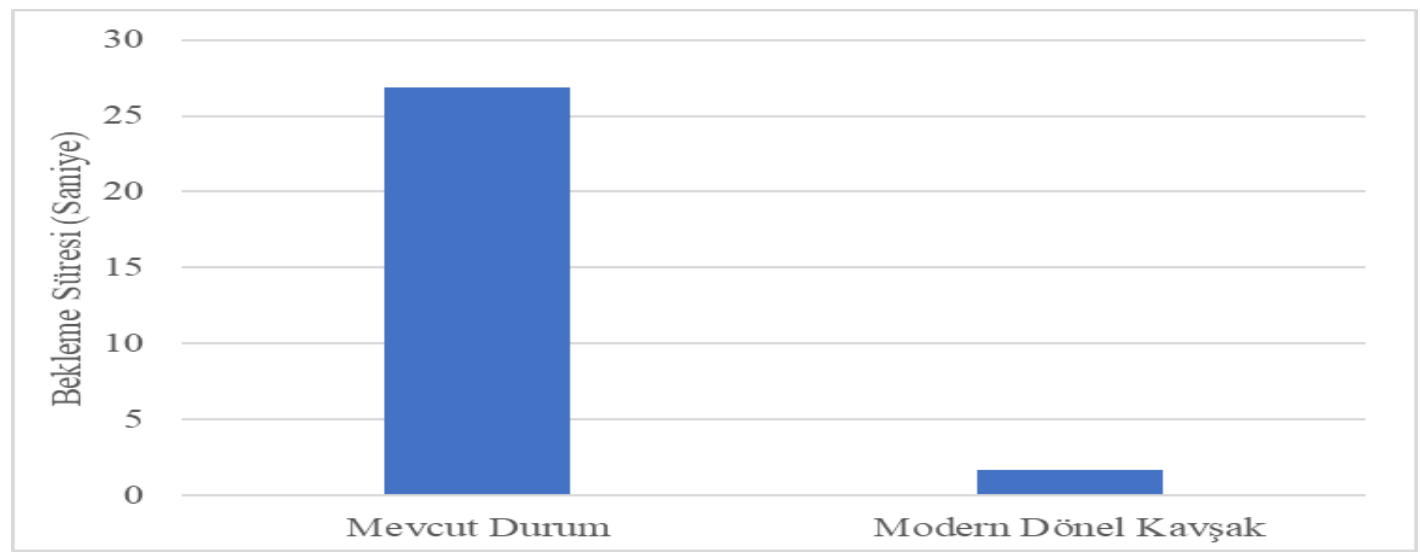

Şekil 6. Bekleme Süreleri

Modern Dönel kavşakta gecikme süresinin ortalaması genel olarak sinyalizasyona sahip bir kavşağa göre daha az çıkmaktadır (KGM, 2005; KGM, 2020). Yapılan analiz sonucunda da modern dönel kavşakta oluşan gecikme süresinin daha az çıktığı görülmektedir. Maliyet açısından kavşak yapımı için gerekli geometri, mevcut geometriye göre daha geniş olduğu için kamulaştırma çalışması gerektirmektedir.

\subsection{Alt Geçit şeklinde farklı düzey kavşak yapılması}

Mevcut durumdaki yönlere göre trafik dağılımı dikkate alındığında Doğu-Batı ve Batı-Doğu yönlerinden gelen trafik hacmi toplam trafik hacminin \%67'sini oluşturduğu görülmektedir. Bu dağılım dikkate alınarak Doğu-Batı ve Batı-Doğu istikametinde altgeçit uygulaması önerilmiştir. Önerilen alt geçit uygulamasının modeli Şekil 7'de verilmiştir. Alt geçidin geometrisi oluşturulurken mevcut geometri göz önünde tutulmuş ve buna uygun olarak tasarlanmıştır. Şekil 8'de bu alternatife ait gecikme süreleri ve mevcut durum ile karşılaştırması verilmiştir.

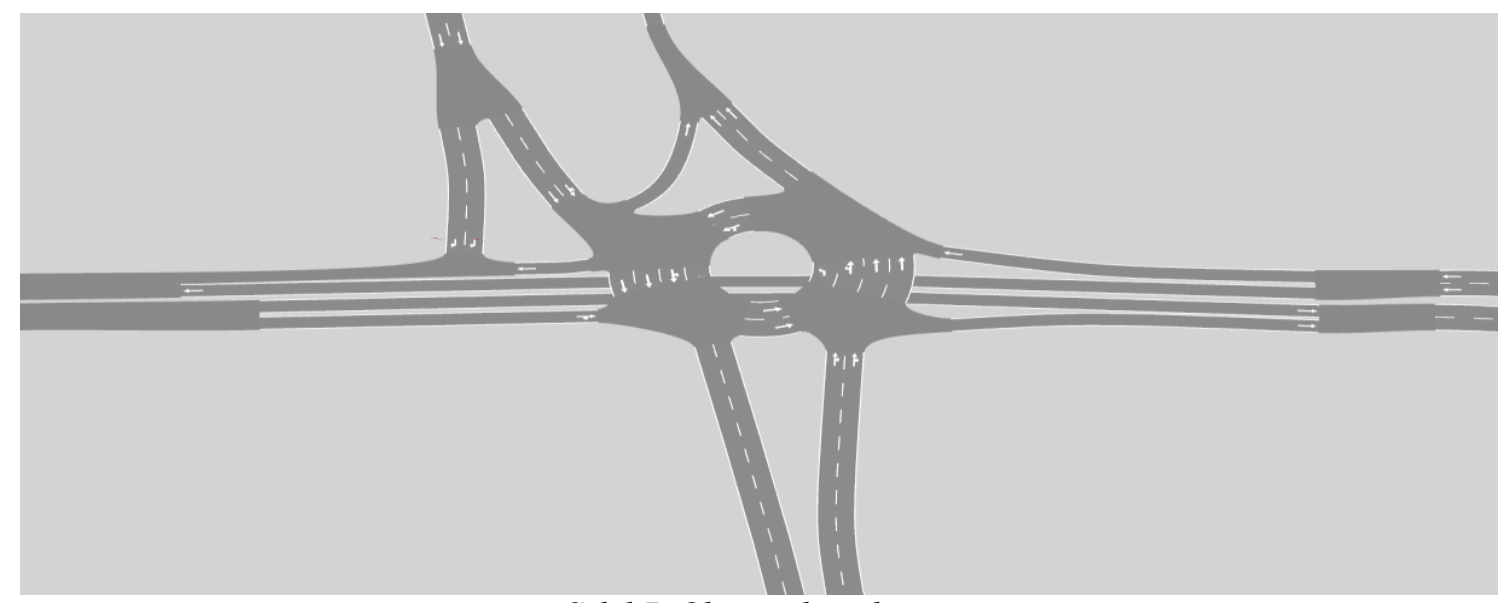

Şekil 7. Oluşturulan altgeçit

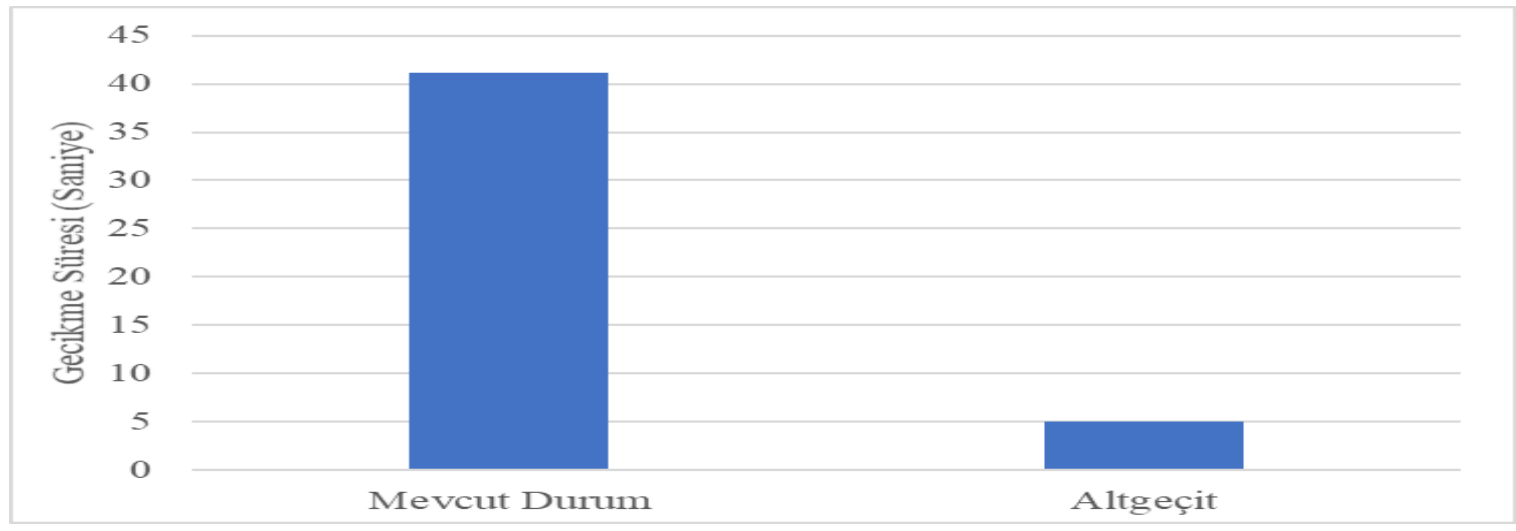

Şekil 8. Gecikme Süreleri 


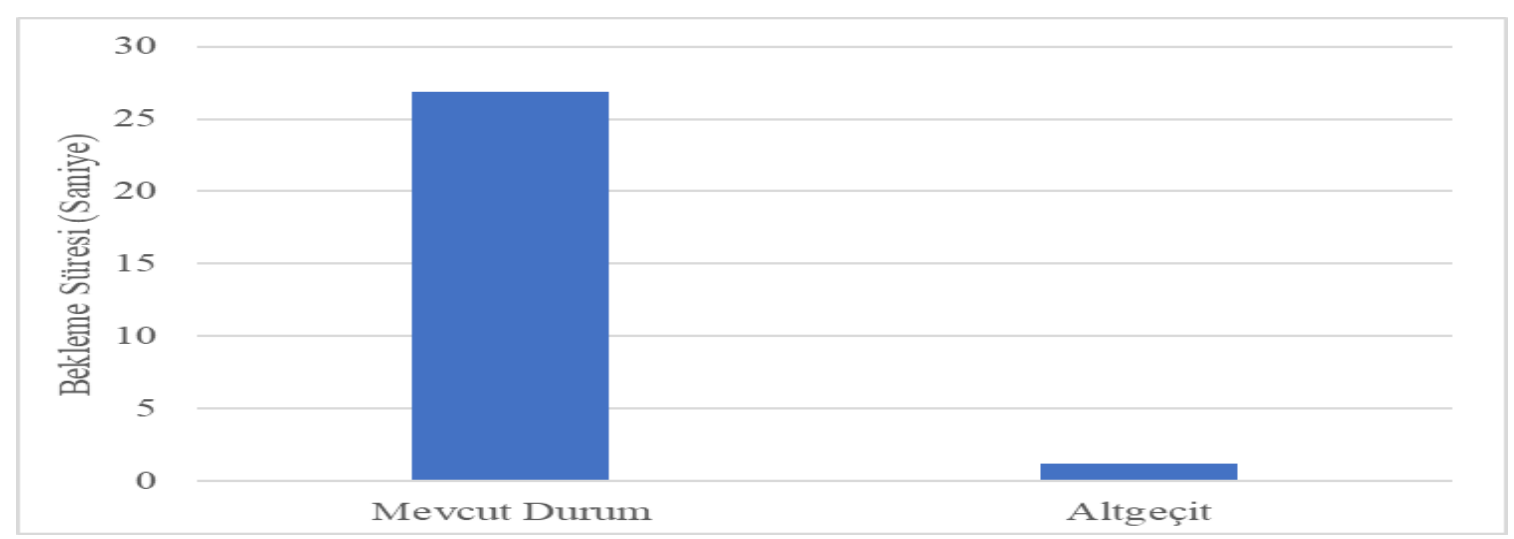

Şekil 9. Bekleme Süreleri

Altgeçit uygulaması Şekil 8'de görüldüğü gibi gecikme süresi değerlerini düşürmüştür. Şekil 9'da bekleme süreleri karşılaştırması gösterilmektedir. Bu kriterlere göre en uygun alternatif altgeçit uygulaması olmuştur. Ancak yapım açısından en maliyetli alternatiftir.

\section{Sonuç}

Bu çalı̧̧mada elde edilen sonuçlar aşağıda verilmiştir;

- Modern dönel kavşak (Roundabout) alternatifinde gecikmeler mevcut durumla karşılaştırıldığında \%78 oranında azalmıştır. Bekleme süresi açısından mevcut durumla karşılaştırıldığında \%94 oranında bir azalma olmuştur. Tercih edilebilir bir alternatiftir.

- Alt geçit alternatifinde gecikmeler mevcut durumla karşılaştırıldığında \%88 oranında azalmış̧ır, bekleme süresi ise $\% 96$ oranında azalmıştır. Kriterlere göre en uygun alternatif olmakla birlikte yüksek yapım maliyeti açısından uygun değildir.

- AIMSUN programı bir kavşağın mevcut durumu ile alternatif seçenekleri modelleme ve değerlendirmede uygun bir programdir.

- Yapılabilirlik açısından en uygun seçenek modern dönel kavşaktır.

- Erzurum ilinde özellikle trafik hacimlerinin yüksek olmasından dolayı doğu-batı istikametindeki tüm kavşakların bir koridor boyunca incelenmesi gerekmektedir.

\section{Kaynakça}

Alkheder, S. (2016) Learning from the past: traffic safety in the eyes of affected local community in Abu Dhabi City, United Arab Emirates. Transportation Letters. 1-19.

Alomari, A.H., Al-Deek, H., Sandt, A., Rogers, J.H. and Hussain, O. (2016) Regional Evaluation of Bus Rapid Transit with and Without Transit Signal Priority. Transportation Research Record: Journal of the Transportation Research Board. 2554, 46-59.

Bayata, H. F. ve Bayrak, O. Ü. (2018). Yeni Yapılması Planlanan bir Kavşağın Mikro-Simülasyon ile Değerlendirilmesi. Erzincan Üniversitesi Fen Bilimleri Enstitüsü Dergisi 11(3): 550-559.

GDH (General Directorate of Highways) (2006) Trafik ve ulas, Im bilgileri. GDH, Ankara, Turkey (in Turkish).

Gomes, G., May, A., and Horowitz, R. (2004) Congested freeway microsimulation model using VISSIM. Transportation Research Record: Journal of the Transportation Research Board. 1876, 71-81.

GoogleEarth (2020). Google Earth. https://www.google.com/earth/. (7.02.2020)

Jeihani, M., et al., Traffic recovery time estimation under different flow regimes in traffic simulation. Journal of Traffic and Transportation Engineering (English Edition), 2015. 2(5): p. 291-300.

Karakikes, I., Spangler, M. and Margreiter, M. (2016) Motorway Network Simulation Using Bluetooth Data. Transport and Telecommunication Journal. 17(3), 242-251.

KGM (2005). Karayolu Tasarım El Kitabı, Karayolları Genel Müdürlüğü Yayınları, 297 s, Ankara.

KGM (2020); Modern Dönel Kavşak kullanımı. Karayolları Genel Müdürlüğü https://www.kgm.gov.tr/Sayfalar/KGM/SiteTr/Trafik/TrafikModernDonelKavsak.aspx

Oketch, T. and M. Carrick. Calibration and validation of a micro-simulation model in network analysis. in Proceedings of the 84th TRB Annual Meeting, Washington, DC. 2005.

Park, B. and Schneeberger, J. (2003) Microscopic Simulation Model Calibration and validation: case study of VISSIM simulation model for a coordinated actuated Signal system. Transportation Research Record: Journal of the Transportation Research Board. $1856,185-192$.

Russo, C.S., The Calibration and Verification of Simulation Models for Toll Plazas. 2008, University of Central Florida Orlando, Florida.

Shankar, K., C. Prasad, and T. Reddy, Evaluation of Area Traffic Management Measures Using Microscopic Simulation Model. Procedia-Social and Behavioral Sciences, 2013. 104: p. 815-824. 
Siddharth, S. and G. Ramadurai, Calibration of VISSIM for Indian Heterogeneous Traffic Conditions. Procedia-Social and Behavioral Sciences, 2013. 104: p. 380-389.

Siddharth, S. and Ramadurai, G. (2013) Calibration of VISSIM for Indian heterogeneous traffic conditions. Procedia-Social and Behavioral Sciences. 104, 380-389.

Song, G., Yu, L. and Zhang, Y. (2012) Applicability of traffic microsimulation models in vehicle emissions estimates: Case study of VISSIM. Transportation Research Record: Journal of the Transportation Research Board. 2270, 132-141.

Tanyel, S. and N. Yayla, Yuvarlakada kavşakların kapasiteleri üzerine bir tartışma. İMO Teknik Dergi, 2010. 21(1): p. 4935-4958.

Tianzi, C., Shaochen, J., and Hongxu, Y. (2013) Comparative Study of VISSIM and SIDRA on Signalized Intersection. ProcediaSocial and Behavioral Sciences. 96, 2004- 2010.

TÜIK (2020); Yıllara göre il nüfusları. Türkiye İstatistik Kurumu $\quad(09.03 .2020)$ http://www.tuik.gov.tr/PreIstatistikTablo.do?istab_id=1590

Yu, L., Yu, L., Chen, X., and Guo, J. (2006) Calibration of VISSIM for bus rapid transit systems in Beijing using GPS data. Journal of Public Transportation. 9(3), 13.

Zlatkovic, M., Zlatkovic, S., Sullivan, T., Bjornstad, J. and Shahandashti, S.K.F. (2019). Assessment Of Effects Of Street Connectivity On Traffic Performance And Sustainability Within Communities And Neighborhoods Through Traffic Simulation. Sustainable Cities and Society 46: 101409. 